\title{
Implication of the Life-Sustaining Treatment Decisions Act on End-of-Life Care for Korean Terminal Patients
}

\author{
Jung Sun Kim, MD ${ }^{1}$ \\ Shin Hye Yoo, MD, MS² \\ Wonho Choi, RN2 \\ Yejin Kim, SW2 \\ Jinui Hong, RN, MS 2 \\ Min Sun Kim, MD, MS',3 \\ Hye Yoon Park, MD, PhD2,4 \\ Bhumsuk Keam, MD, PhD ${ }^{1,2}$ \\ Dae Seog Heo, MD, PhD',2
}

${ }^{1}$ Department of Internal Medicine,

${ }^{2}$ Center for Palliative Care and Clinical Ethics,

Departments of ${ }^{3}$ Pediatrics and

${ }^{4}$ Psychiatry, Seoul National University

Hospital, Seoul, Korea

Correspondence: Dae Seog Heo, MD, PhD

Department of Internal Medicine,

Seoul National University Hospital,

101 Daehak-ro, Jongno-gu, Seoul 03080, Korea

Tel: 82-2-2072-2857

Fax: 82-2-742-6689

E-mail: heo1013@snu.ac.kr

Received November 28, 2019

Accepted March 20, 2020

Published Online March 23, 2020

*Jung Sun Kim and Shin Hye Yoo contributed equally to this work.

\begin{abstract}
Purpose
Life-sustaining treatment (LST) decisions for patients and caregivers at the end-of-life (EOL) process are supported by the "Act on Hospice and Palliative Care and Decisions on LST for Patients at the EOL," enforced in February 2018. It remains unclear whether the act changes EOL decisions and LST implementation in clinical practice. For this study, we investigated patients' decision-making regarding LSTs during the EOL process since the act's enforcement.
\end{abstract}

\section{Materials and Methods}

Retrospective reviews were conducted on adult patients who were able to decide to terminate LST and died at Seoul National University Hospital between February 5, 2018, and February 5, 2019. We examined demographics, who made the decisions, the type and date of documentation confirming patient's LST, and whether the LST was withheld or withdrawn.

\section{Results}

Of 809 patients who were enrolled, 29\% ( $n=231)$ completed forms regarding LST themselves, and $71 \%(n=578)$ needed family members to decide. The median time from confirmation of the EOL process to death and from the Advance Statement to death were 2 and 5 days, respectively (both ranges, 0 to 244$)$. In total, $90 \%(n=727)$ of patients withheld treatment, and $10 \%(n=82)$ withdrew it. We found a higher withdrawal rate when family members made the decisions $(13.3 \%$ vs. $1.7 \%, p<0.001)$.

\section{Conclusion}

After the act's enforcement, withdrawing LSTs became lawful and self-determination rates increased. Family members still make $71 \%$ of decisions regarding LSTs, but these are often inconsistent with the patients' wishes; thus, further efforts are needed to integrate the new act into clinical practice.

\section{Introduction}

As medical and technological advances are able to prolong life, patients and family members are often eager to receive aggressive treatment even if patients are close to inevitable death [1,2]. In Korea, over a 10-year period, terminal cancer patients have utilized an increasing amount of aggressive treatments with little curative effects at the end-of-life (EOL) process, including chemotherapy [3]. This trend deteriorates
Key words

Withholding treatment, Palliative care, Advance directives 
mainly occur between physicians and family caregivers $[7,8,10,11]$. Therefore, patients' intents regarding life-sustaining treatment (LST) cannot be respected. Most do-not-resuscitate (DNR) orders only indicate that cardiopulmonary resuscitation (CPR) should not be performed in the event of cardiac arrest, which may not entirely reflect the patients' will. The "Act on Hospice and Palliative Care and Decisions on LST for Patients at the EOL" went into effect on February 4, 2018 in Korea, and its goal is to assure the best interest of the patients and to respect their self-determination rights [12].

However, it remains unclear whether the act changes EOL discussion process or influences decisions on LST in clinical practice. Therefore, we conducted this study to investigate the status of decision-making for LST during the EOL process, after the enforcement of the act.

\section{Materials and Methods}

\section{Study design, patients, and data collection}

We performed single-center, retrospective study of adult patients who legally terminated LST and died at Seoul National University Hospital (SNUH) between February 5, 2018, and February 5, 2019, the first year after the act was enforced. The SNUH is a 1,779-bed tertiary referral hospital in the Republic of Korea, where a total of 1,400 doctors work in mainly acute and specialized care. It does not have an inpatient hospice-palliative care unit.

We excluded patients who were younger than 19 years old, had incomplete legal forms, had previously signed DNR forms, or had no documentation in electronic medical records (EMR).

We reviewed the EMR of the final admission for patients in their EOL process for data including demographics (age, sex, and residence), comorbidities (using Charlson comorbidity index [CCI]), intensive care unit (ICU) admission, and status of critical care. We obtained data from the EMR and the database of Korea National Institute for Bioethics Policy concerning type of legal forms confirming patient's intent regarding LST, decision-makers, date of documentation, and whether the LST was withheld or withdrawn.

\section{Definition and measurement}

The act adopted two main concepts: "terminal phase" and "EOL process." The "terminal phase" is defined as the period when fundamental recovery is not possible despite aggressive treatment, and it is accompanied by a gradual worsening of symptoms. The "EOL process" is when death is imminent with no possibility of recovery, and there is a rapid worsening of symptoms despite treatment. In general, the terminal phase is defined as the period of inexorable and irreversible decline in functional status before death [13]. However, in this study, we used the legal term mentioned in the act.

The LST refers to medical treatment that merely extend the duration of the EOL process without curative effect. The act defines LST as CPR, mechanical ventilation (MV), renal replacement therapy (RRT), and chemotherapy. It makes withholding and withdrawing LST possible with the legal determination form. For the patient at the EOL process, "withholding" means not performing LST at all, and "withdrawing" means terminating LST that the patient is already receiving. We defined "critical care" as CPR, MV, or RRT performed before confirmation of the EOL process.

To withhold or withdraw LST, three steps are required. First, two physicians (the primary physician and one medical specialist) must confirm that a patient is at the EOL process (form 9). Second, a patient should express his or her intention in person with an advance statement regarding LST or form 1 (LST plan). When the patient lacks "decision-making capacity," family members take on this role and must provide two or more identical statements regarding patient's intent to withhold or withdraw LST (form 11). When it is impossible to verify a patient's intent, "all" members of patient's family should show unanimous consensus on withholding or withdrawing LST (form 12). The "patient's family" herein refers to all of immediate family members who are 19 years of age or older. Finally, primary physician should write the execution form (form 13), clarifying which LST to withhold or withdraw, and implement any necessary action.

To investigate the current status of decision making for LST since the act was put into effect, we measured the number of days from (1) the date of form 9 and (2) the date of form 1 to death. We reviewed (3) how withholding or withdrawing LST was performed in practice, (4) whether or which critical care was performed, and (5) place of death within the hospital. Additionally, we examined the ICU admission rate for terminal cancer patients' final month.

\section{Statistical analysis}

We used descriptive data such as median, range of value, and the number of patients (expressed as a percent) to illustrate the demographics and clinical characteristics of patients. To analyze data between different decision-makers, we applied Student $t$ test for continuous variables and chisquare test for categorical variables. For the analysis of critical care, among 809 patients, the rates of those who were given CPR, MV, and RRT before and after documentation of form 9 were separately calculated. We considered a p-value 


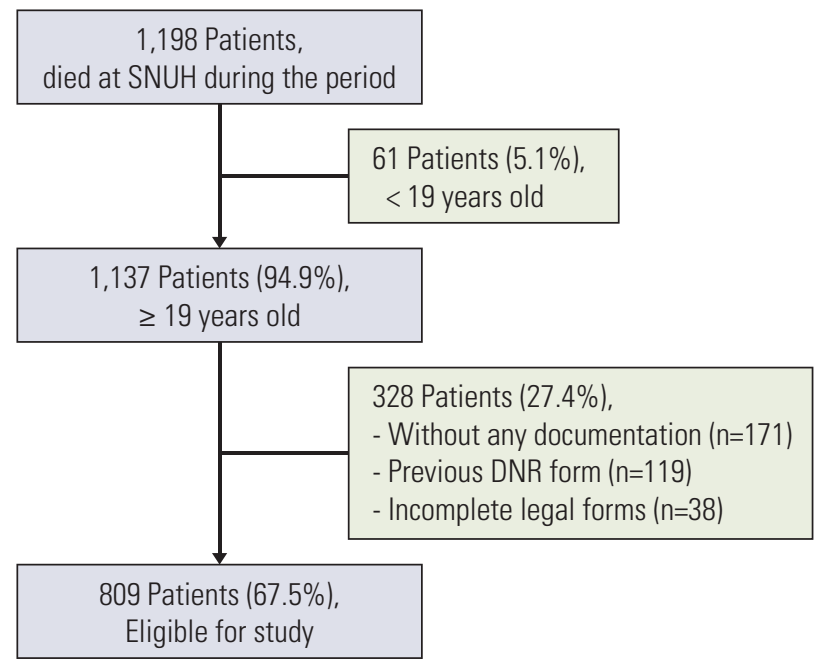

Fig. 1. Flow chart. SNUH, Seoul National University Hospital; DNR, do-not-resuscitate.

of less than 0.05 to be statistically significant. Statistical analysis was performed using STATA ver. 12.0 (StataCorp LP, College Station, TX).

\section{Ethical statement}

The study protocol was reviewed and approved by the institutional review board of the SNUH (No. H-1907-1711050). We conducted the study in accordance with the Principles of the Declaration of Helsinki. Informed consent was obtained from all individual participants included in the study.

\section{Results}

A total of 1,198 patients died at SNUH between February 5, 2018, and February 5, 2019. Among them, we excluded patients who were younger than 19 years old $(n=61)$, had incomplete legal forms $(\mathrm{n}=38)$, had previously signed DNR forms $(\mathrm{n}=119)$, or had no documentation in EMR $(\mathrm{n}=171)$. To summarize, data from 809 adult patients who died at SNUH with complete legal forms during the period were reviewed (Fig. 1). Demographics and clinical characteristics of the patients are summarized in Table 1, in which the CCI score shows a marked burden of comorbid diseases [14]. The median number of comorbidities was 6 , with metastatic solid tumors (45.4\%) being the most common, followed by uncomplicated diabetes mellitus $(19.4 \%)$, cerebral vascular disease $(15.3 \%)$, and moderate to severe chronic kidney disease (12.5\%). Terminal cancer comprised $70.0 \%$ of the terminal diagnoses, which accurately represents our study population, consisting of $71.1 \%$ of the patients $(575 / 809)$.

\section{Documentation of the legal forms and decision-makers}

Among 809 patients, 231 (29\%) completed forms in person, and $578(71 \%)$ had family members complete the forms. To evaluate the interval between documentation and death, we divided forms into ones that were documented during the EOL process and ones before then. With the former, it took a median of 2 days (range, 0 to 244 days) from documentation to death. The interval was longer when patients documented forms in person than when family members did (4 days vs. 1 day). From the time patients show their intent, the median amount of time was 5 days (range, 0 to 244 days) (Table 2).

\section{Withholding or withdrawing LST}

In practice, 727 patients $(89.9 \%)$ withheld and $82(10.1 \%)$ withdrew the LST. Regarding decision-makers, the rate of withholding LST was higher when the forms were signed by patients themselves rather than when family members were involved ( $98.3 \%$ vs. $86.5 \%$ ) (Fig. 2 A).

Among 82 patients who withdrew LST, three patients (3.7\%) stopped CPR, 74 (90.2\%) discontinued MV, four (4.9\%) discontinued RRT, and four (4.9\%) terminated other treatments including bilevel positive airway pressure and extracorporeal membrane oxygenation (Fig. 2B).

\section{Status of "Critical Care"}

We assessed how critical care was administered in "the last" admission, according to the documentation date of form 9. In total, CPR (12\%), MV (37.8\%), and RRT (21.9\%) were performed before documentation of the cases, but after documentation, the execution rate of these LSTs dropped to $0.5 \%, 26.1 \%$, and $15.5 \%$, respectively. Overall, patients experienced critical care at a higher frequency when discussing LST with family members (Fig. 3A-C).

\section{ICU admission in the last month of life in terminal can- cer patients}

From a previous study, it is known that cancer care near the EOL process is becoming increasingly aggressive [3]. To see how this was affected by the act, we analyzed the data of 575 terminal cancer patients. In their final month, 30.3\% $(174 / 575)$ of them admitted to the ICU. ICU admission rate was clearly lower when patients signed the legal forms themselves rather than when family members did ( $14 \%$ vs. $39 \%)$ 
Table 1. Demographics and clinical characteristics

\begin{tabular}{|c|c|c|c|c|c|}
\hline Characteristic & $\begin{array}{c}\text { Total } \\
(n=1,198)\end{array}$ & $\begin{array}{l}\text { Complete legal } \\
\text { forms }(n=836)\end{array}$ & $\begin{array}{l}\text { Incomplete legal } \\
\text { forms }(n=39)\end{array}$ & $\begin{array}{c}\text { Previous DNR } \\
\text { form }(n=120)\end{array}$ & $\begin{array}{l}\text { Without any } \\
\text { forms }(n=203)\end{array}$ \\
\hline \multicolumn{6}{|l|}{ Age (yr) } \\
\hline Median (range) & $66(0-102)$ & $66(0-98)$ & $61(0-80)$ & $72(0-102)$ & $65(0-98)$ \\
\hline$\geq 19$ & 1,137 (94.9) & $809(96.8)$ & $38(97.4)$ & $119(99.2)$ & $171(84.2)$ \\
\hline$<19$ & $61(5.1)$ & $27(3.2)$ & $1(2.6)$ & $1(0.8)$ & $32(15.8)$ \\
\hline \multicolumn{6}{|l|}{ Sex } \\
\hline Male & $732(62.0)$ & $524(62.7)$ & $21(53.8)$ & $79(65.8)$ & $119(58.6)$ \\
\hline Female & $455(38.0)$ & $312(37.3)$ & $18(46.1)$ & $41(34.2)$ & $84(41.4)$ \\
\hline \multicolumn{6}{|l|}{ Residence } \\
\hline Seoul & $709(59.2)$ & $469(56.1)$ & $24(61.5)$ & $85(70.8)$ & $131(64.5)$ \\
\hline Metropolitan & 207 (17.3) & $149(17.8)$ & $8(20.5)$ & $13(10.8)$ & $37(18.2)$ \\
\hline Suburban & $282(23.5)$ & $218(26.1)$ & $7(18.0)$ & $22(18.3)$ & $35(17.3)$ \\
\hline \multicolumn{6}{|l|}{ Comorbidities } \\
\hline Myocardial infarction & $119(9.9)$ & $76(9.1)$ & $1(2.6)$ & $17(14.2)$ & $25(12.3)$ \\
\hline Congestive heart disease & $90(7.5)$ & $59(7.1)$ & $1(2.6)$ & $8(6.7)$ & $22(10.8)$ \\
\hline Peripheral vascular disease & $20(1.7)$ & $9(1.1)$ & $1(2.6)$ & $4(3.3)$ & $6(3.0)$ \\
\hline Cerebral vascular disease & $183(15.3)$ & $121(14.5)$ & $2(5.1)$ & $37(30.8)$ & $23(11.3)$ \\
\hline Dementia & $34(2.8)$ & $23(2.8)$ & 0 & $5(4.2)$ & $6(3.0)$ \\
\hline COPD & $31(2.6)$ & $24(2.9)$ & 0 & $3(2.5)$ & $4(2.0)$ \\
\hline Rheumatic disease & $1(0.1)$ & $1(0.1)$ & 0 & 0 & 0 \\
\hline Peptic ulcer disease & $51(4.3)$ & $33(3.9)$ & $2(5.1)$ & $11(9.2)$ & $5(2.5)$ \\
\hline \multicolumn{6}{|l|}{ Liver disease } \\
\hline Mild & $70(5.8)$ & $54(6.5)$ & $1(2.6)$ & $7(5.8)$ & $8(3.9)$ \\
\hline Moderate to severe & $130(10.8)$ & $92(11.0)$ & $3(7.7)$ & $17(14.2)$ & $18(8.9)$ \\
\hline \multicolumn{6}{|l|}{ Diabetes } \\
\hline Uncomplicated & $232(19.4)$ & $161(19.3)$ & $5(12.8)$ & $29(24.2)$ & $37(18.2)$ \\
\hline Complicated & $49(4.1)$ & $30(3.6)$ & 0 & $9(7.5)$ & $10(4.9)$ \\
\hline Hemiplegia & $7(0.6)$ & $4(0.5)$ & 0 & $1(0.8)$ & $2(1.0)$ \\
\hline \multicolumn{6}{|l|}{ Chronic kidney disease } \\
\hline Moderate to severe & $150(12.5)$ & 97 (11.6) & $2(5.1)$ & $24(20.0)$ & $27(13.3)$ \\
\hline \multicolumn{6}{|l|}{ Malignancy } \\
\hline Localized & $117(9.8)$ & $82(9.8)$ & $1(2.6)$ & $19(15.8)$ & $15(7.4)$ \\
\hline Metastatic & $544(45.4)$ & $450(53.8)$ & $32(82.1)$ & $31(25.8)$ & $31(15.3)$ \\
\hline Leukemia & $66(5.5)$ & $57(6.8)$ & $2(5.1)$ & $2(1.7)$ & $5(2.5)$ \\
\hline Lymphoma & $59(4.9)$ & $47(5.6)$ & $1(2.6)$ & $5(4.2)$ & $6(3.0)$ \\
\hline Human immunodeficiency virus & $3(0.3)$ & $2(0.2)$ & $1(2.6)$ & 0 & 0 \\
\hline \multicolumn{6}{|l|}{ Charlson comorbidity index score } \\
\hline Median (range) & $6(0-15)$ & $6(0-15)$ & $6(0-12)$ & $4(0-10)$ & $1(0-15)$ \\
\hline Mean \pm SD & $4.5 \pm 2.9$ & $5.0 \pm 2.7$ & $5.9 \pm 2.4$ & $4.0 \pm 2.6$ & $2.5 \pm 2.8$ \\
\hline $0-2$ & $373(31.1)$ & $203(24.3)$ & $6(15.4)$ & $39(32.5)$ & $125(61.6)$ \\
\hline $3-4$ & $170(14.2)$ & $110(13.2)$ & $1(2.6)$ & $30(25.0)$ & $29(14.3)$ \\
\hline$>4$ & $655(54.7)$ & $523(62.6)$ & $32(82.0)$ & $51(42.5)$ & $49(24.1)$ \\
\hline \multicolumn{6}{|l|}{ Terminal diagnosis } \\
\hline Yes & $771(64.4)$ & $624(74.6)$ & $35(89.7)$ & $53(44.2)$ & $59(29.1)$ \\
\hline Cancer & $707(59.0)$ & $585(70.0)$ & $34(87.2)$ & $41(34.2)$ & $47(23.2)$ \\
\hline Liver cirrhosis & $78(6.5)$ & $47(5.6)$ & $3(7.7)$ & $13(10.8)$ & $15(7.4)$ \\
\hline COPD & $17(1.4)$ & $11(1.3)$ & 0 & $2(1.7)$ & $4(2.0)$ \\
\hline AIDS & $1(0.1)$ & $1(0.1)$ & 0 & 0 & 0 \\
\hline No & 427 (35.6) & $212(25.4)$ & $4(10.3)$ & $67(55.8)$ & $144(70.9)$ \\
\hline
\end{tabular}

Values are presented as number (\%) unless otherwise indicated. DNR, do-not-resuscitate; COPD, chronic obstructive pulmonary disease; SD, standard deviation; AIDS, acquired immune deficiency syndrome. 
Table 2. Intervals between documentation and death

\begin{tabular}{|c|c|c|c|c|c|c|}
\hline \multirow{3}{*}{$\begin{array}{l}\text { Decision-makers } \\
\text { Patient } \\
(\mathrm{n}=231,29 \%)\end{array}$} & \multirow{3}{*}{$\begin{array}{l}\text { Type of the legal forms } \\
\text { Form } 1 \\
\text { (terminal phase) }\end{array}$} & \multirow{3}{*}{$\begin{array}{l}\text { No. }(\%) \\
31(3.6)\end{array}$} & \multicolumn{4}{|c|}{ Median (range) } \\
\hline & & & \multicolumn{2}{|c|}{$\begin{array}{l}\text { Days between } \\
\text { form } 9 \text { and death }\end{array}$} & \multicolumn{2}{|c|}{$\begin{array}{c}\text { Days between } \\
\text { form } 1 \text { or advance } \\
\text { statement and death }\end{array}$} \\
\hline & & & $1(0-51)$ & $4(0-244)$ & $17(3-235)$ & $5(0-244)$ \\
\hline & $\begin{array}{l}\text { Form } 1 \\
\text { (end-of-life process) }\end{array}$ & $191(23.3)$ & $4(0-244)$ & & $4(0-244)$ & \\
\hline & $\begin{array}{l}\text { Form } 10 \text { (advance } \\
\text { statement verification) }\end{array}$ & $9(1.0)$ & $0(0-20)$ & & $33(2-220)$ & \\
\hline \multirow{2}{*}{$\begin{array}{l}\text { Family members } \\
(\mathrm{n}=578,71 \%)\end{array}$} & Form 11 ( $\geq 2$ members) & $349(41.8)$ & $2(0-173)$ & $1(0-173)$ & & \\
\hline & Form 12 (all members) & $229(30.1)$ & $1(0-167)$ & & & \\
\hline Total $(\mathrm{n}=809)$ & & & $2(0-244)$ & & & \\
\hline
\end{tabular}

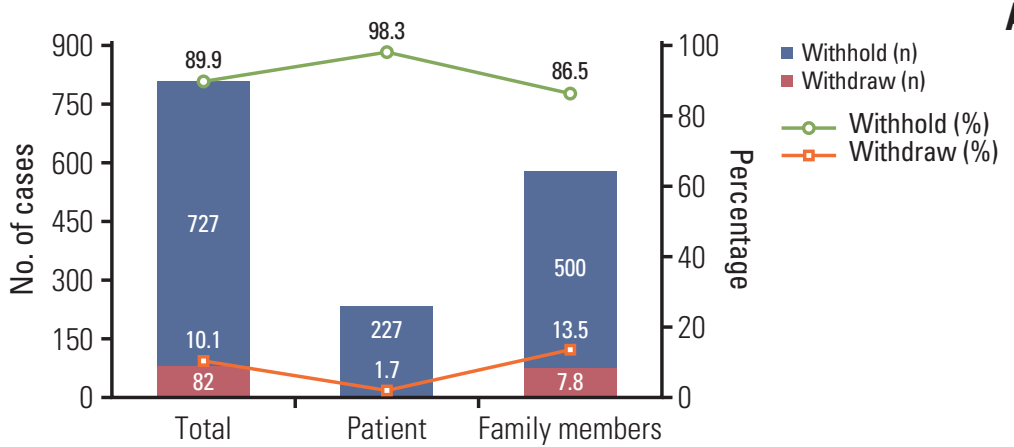

A

Fig. 2. Implementation status of life-sustaining treatment in the first year of the act's enforcement. (A) Withholding ( $\mathrm{n}=727$ ) or withdrawing $(n=82)$ rate in total, and by decision-makers. (B) Proportions of the treatment which were withdrawn, such as cardiopulmonary resuscitation (CPR), mechanical ventilation (MV), renal replacement therapy (RRT), and others.

(Fig. 4). Additionally, more patients died in ICU (29.9\% vs. $5 \%$ ) when family members made the decisions.

\section{Discussion}

Our study found that self-determination rate on LST has increased by up to $29 \%$ since the enforcement of the act, which is higher than those from previous studies [3,7,10,11,15]. In Korea, physicians tend to avoid telling the truth to patients directly, concerned that they might be frightened or depressed, so family caregivers are frequently surrogate decisionmakers, and do not always respect the patient's will [11]. However, patients want to know their disease status [16] and discuss ACP in person [17]. Not considering patient's own values, wishes, and goals may result in unnecessary LSTs [18] and deteriorate quality of life for patients and caregivers $[4,5]$. Our finding implies that patients have been more likely to discuss ACP with their physicians and family caregivers since the act's enforcement. However, the self-determination rate from this study is lower than the rates from Western countries $[19,20]$, so further efforts are needed to enable selfdetermination by patients themselves.

To date, many ethicists and judges have concurred that there is no moral difference between withholding and withdrawing LST [21,22]. Yet, in majority of Asian countries, the public, patients, and even some physicians tend to understand and treat the two concepts differently [23]. Before the act, withholding LST was accepted, but the first case of withdrawing LST for a person who has no chance of recovery was 


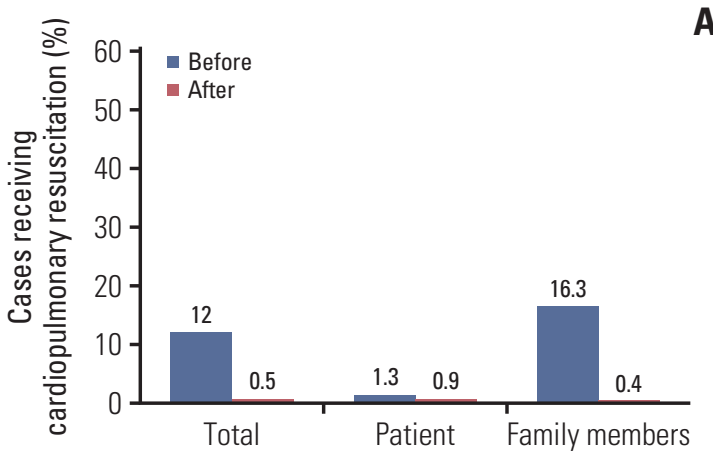

A
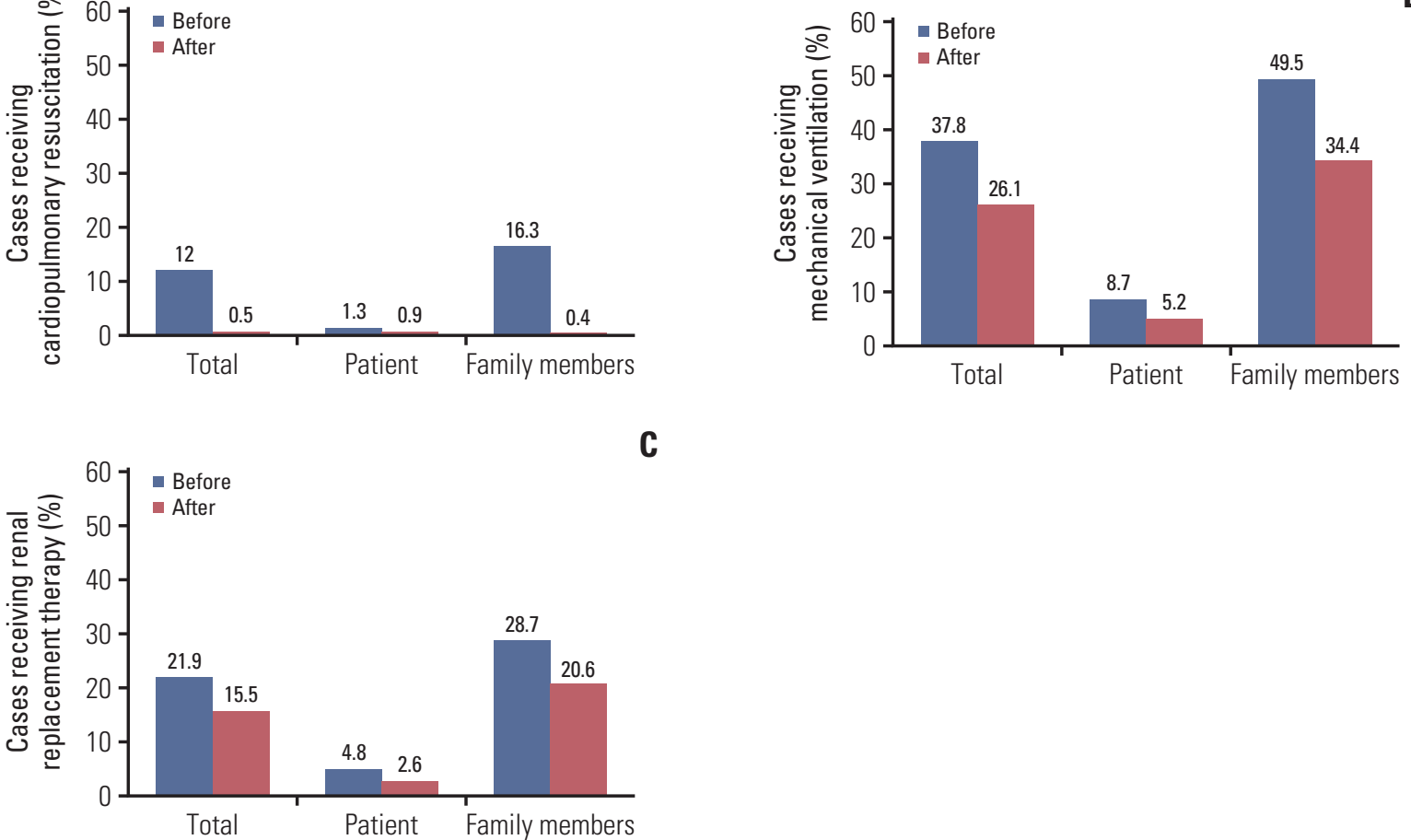

Fig. 3. Status of critical care (\%) such as cardiopulmonary resuscitation (A), mechanical ventilation (B), and renal replacement therapy $(\mathrm{C})$, before and after documentation of the legal form 9.

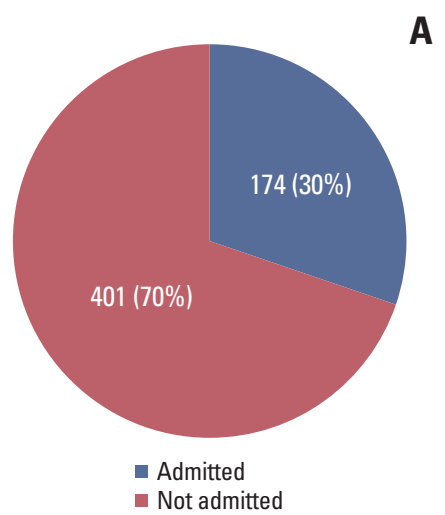

A

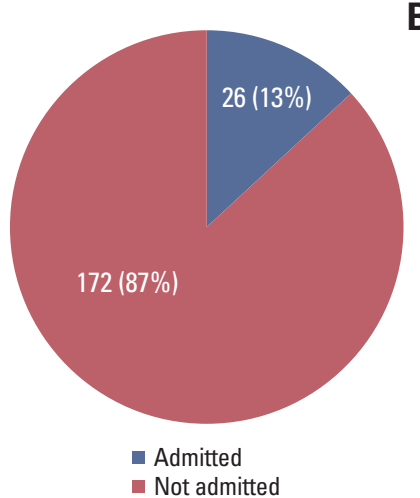

B

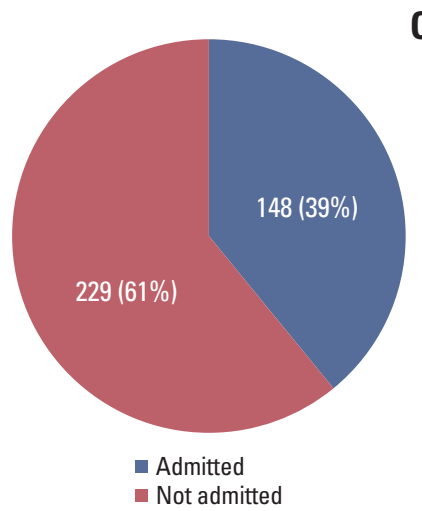

Fig. 4. Intensive care unit (ICU) utilization in the last month of life in terminal cancer patients. (A) ICU admission rate by decision-makers in the first year of the act's enforcement. Admission patterns when patients (B) or family (C) members made decisions.

a result of prolonged litigation in the so-called Grandma Kim case in 2009. After the legitimation following that "case," patients were lawfully able to withdraw LST and $10 \%$ of selfdetermination led to termination in this study. Supposedly its justification would have alleviated physicians' guilty feelings.
From the aspect of "critical care," however, patients underwent CPR, MV, and RRT in $12 \%, 38 \%$, and $22 \%$, respectively in their last admission. As critical care turns into LST after confirmation of the EOL process, decision to withhold means not starting additional LST rather than terminating ongoing treatments in a patient who is already on critical care. There- 
fore, even in patients who decided to withhold LST, a considerable percentage actually experienced critical care.

High ICU admission rate $(30.3 \%)$ within the last month before death in patients with terminal cancer was consistent with those from the previous study [3], even it seems to be on the rise. This reflects high level of aggressive care utilization at the EOL and implies pathetic practice in terminal cancer patients $[3,18]$, the majority of the study population. DNR rather than legal form had been used in 2002 and 2012, and discussion for decision making on LST in those periods differed from 2018, so ICU admission rate could not be directly compared between 2018 and previous periods. However, we propose that ICU admission rate in terminal cancer patients is still high, even after enforcement of the act.

Our finding showed that decisions regarding LST made by family members are different from those made by patients in person. Decisions by family members were significantly associated with higher rates of withdrawal and critical care use, suggesting caregivers' obsession with LST. Cultural aspects including filial piety, the belief that doing everything possible is the best, and unease in accepting death could explain those situations. The difference in implementation of LST by decision-makers compared to patients raises the issue that patients could receive over-treatment not in line with their wishes. Patients' intent and best interest should be taken into consideration during EOL discussion, especially when the patient lacks the capacity for decision-making.

Although decision making occurs earlier than before $[24,25]$ given that the interval from advance statement to death was median of 33 days, it does not seem sufficient enough for all the patients to be able to make decision themselves. Additionally, in Korea, DNR orders are usually written in a week before dying $[7,9,15]$, which means that most of them are documented without proper ACP. To be more effective, we should consider initiating ACP discussion when a patient is diagnosed with critical or terminal illness $[17,26]$. However, short outpatient consultation time [27], communication difficulties [26], or patients' inaccurate understanding of illness $[1,28]$ may hinder early initiation of ACP. Yet we shall observe further progress since the results are based on 1 -year data after the act's enforcement, consisting only $1 \%$ of study population.

In the act, since terminating LST is possible only after physicians confirm that a patient is at the EOL process, uncertainties could be hurdles for the implementation process. Our study demonstrates that the confirmation is done at a median of 2 days before death, but the wide range ( 0 to 244 days) implies difficulty in further prediction [26]. In order for physicians to make decisions with less struggle, a general consensus should be settled.

There are a few limitations in our study. First, it alone cannot represent the practice pattern of a whole country since it is a study from a single tertiary hospital with mainly cancer patients. Therefore, further studies should be conducted in various institutional settings. Hopefully, investigating a nationwide database would provide more information on strengths and limitations of the act. Second, since this study is based on retrospective data, we should be cautious when interpreting causal relationships. Prospective cohort studies are warranted to overcome this issue.

In conclusion, this study showed that terminating LST became possible, and the self-determination rate actually rose in the clinical practice after the act's enforcement. Considering that patterns of the implementation differed according to who made decisions regarding LST, further efforts are needed to assure best interest and self-determination rights of patients.

\section{Conflicts of Interest}

Conflict of interest relevant to this article was not reported.

\section{Acknowledgments}

This research was funded by the Korea National Institute for Bioethics Policy (KoNIBP), awarded by the 2019 Bioethics Policy Research Program.

\section{References}

1. Lee SJ, Fairclough D, Antin JH, Weeks JC. Discrepancies between patient and physician estimates for the success of stem cell transplantation. JAMA. 2001;285:1034-8.

2. Matsuyama R, Reddy S, Smith TJ. Why do patients choose chemotherapy near the end of life? A review of the perspective of those facing death from cancer. J Clin Oncol. 2006;24: 3490-6.
3. Choi Y, Keam B, Kim TM, Lee SH, Kim DW, Heo DS. Cancer treatment near the end-of-life becomes more aggressive: changes in trend during 10 years at a single institute. Cancer Res Treat. 2015;47:555-63.

4. Farber SJ, Egnew TR, Herman-Bertsch JL, Taylor TR, Guldin GE. Issues in end-of-life care: patient, caregiver, and clinician perceptions. J Palliat Med. 2003;6:19-31. 
5. Grunfeld E, Coyle D, Whelan T, Clinch J, Reyno L, Earle CC, et al. Family caregiver burden: results of a longitudinal study of breast cancer patients and their principal caregivers. CMAJ. 2004;170:1795-801.

6. Singer PA, Martin DK, Kelner M. Quality end-of-life care: patients' perspectives. JAMA. 1999;281:163-8.

7. Oh DY, Kim JH, Kim DW, Im SA, Kim TY, Heo DS, et al. CPR or DNR? End-of-life decision in Korean cancer patients: a single center's experience. Support Care Cancer. 2006;14:103-8.

8. Kim DY, Lee KE, Nam EM, Lee HR, Lee KW, Kim JH, et al. Do-not-resuscitate orders for terminal patients with cancer in teaching hospitals of Korea. J Palliat Med. 2007;10:1153-8.

9. Jho HJ, Nam EJ, Shin IW, Kim SY. Changes of end of life practices for cancer patients and their association with hospice palliative care referral over 2009-2014: a single institution study. Cancer Res Treat. 2019;52:419-25.

10. Baek SK, Chang HJ, Byun JM, Han JJ, Heo DS. The association between end-of-life care and the time interval between provision of a do-not-resuscitate consent and death in cancer patients in Korea. Cancer Res Treat. 2017;49:502-8.

11. Lee JK, Keam B, An AR, Kim TM, Lee SH, Kim DW, et al. Surrogate decision-making in Korean patients with advanced cancer: a longitudinal study. Support Care Cancer. 2013;21:183-90.

12. Act on Decisions on Life-Sustaining Treatment for Patients in Hospice and Palliative Care or at the End of Life, No. 14013 (Feb 3, 2016).

13. Hui D, Nooruddin Z, Didwaniya N, Dev R, De La Cruz M, $\mathrm{Kim} \mathrm{SH}$, et al. Concepts and definitions for "actively dying," "end of life," "terminally ill," "terminal care," and "transition of care": a systematic review. J Pain Symptom Manage. 2014;47: 77-89.

14. Charlson ME, Pompei P, Ales KL, MacKenzie CR. A new method of classifying prognostic comorbidity in longitudinal studies: development and validation. J Chronic Dis. 1987;40: 373-83.

15. Kim DY, Lee SM, Lee KE, Lee HR, Kim JH, Lee KW, et al. An evaluation of nutrition support for terminal cancer patients at teaching hospitals in Korea. Cancer Res Treat. 2006;38:214-7.

16. Yun YH, Kwon YC, Lee MK, Lee WJ, Jung KH, Do YR, et al. Experiences and attitudes of patients with terminal cancer and their family caregivers toward the disclosure of terminal illness. J Clin Oncol. 2010;28:1950-7.
17. Park HY, Kim YA, Sim JA, Lee J, Ryu H, Lee JL, et al. Attitudes of the general public, cancer patients, family caregivers, and physicians toward advance care planning: a nationwide survey before the enforcement of the life-sustaining treatment decision-making act. J Pain Symptom Manage. 2019;57:774-82.

18. Yoo SH, Keam B, Kim M, Kim TM, Kim DW, Heo DS. The effect of hospice consultation on aggressive treatment of lung cancer. Cancer Res Treat. 2018;50:720-8.

19. Levin TT, Li Y, Weiner JS, Lewis F, Bartell A, Piercy J, et al. How do-not-resuscitate orders are utilized in cancer patients: timing relative to death and communication-training implications. Palliat Support Care. 2008;6:341-8.

20. van der Heide A, Deliens L, Faisst K, Nilstun T, Norup M, Paci E, et al. End-of-life decision-making in six European countries: descriptive study. Lancet. 2003;362:345-50.

21. Sprung CL, Eidelman LA. Worldwide similarities and differences in the foregoing of life-sustaining treatments. Intensive Care Med. 1996;22:1003-5.

22. Way J, Back AL, Curtis JR. Withdrawing life support and resolution of conflict with families. BMJ. 2002;325:1342-5.

23. Phua J, Joynt GM, Nishimura M, Deng Y, Myatra SN, Chan $\mathrm{YH}$, et al. Withholding and withdrawal of life-sustaining treatments in intensive care units in Asia. JAMA Intern Med. 2015;175:363-71.

24. Kong BH, An HJ, Kim HS, Ha SY, Kim IK, Lee JE, et al. Experience of advance directives in a hospice center. J Korean Med Sci. 2015;30:151-4.

25. Hong JH, Kwon JH, Kim IK, Ko JH, Kang YJ, Kim HK. Adopting advance directives reinforces patient participation in endof-life care discussion. Cancer Res Treat. 2016;48:753-8.

26. Koh SJ, Kim S, Kim J, Keam B, Heo DS, Lee KH, et al. Experiences and opinions related to end-of-life discussion: from oncologists' and resident physicians' perspectives. Cancer Res Treat. 2018;50:614-23.

27. Sohn KH, Nam S, Joo J, Kwon YJ, Yim JJ. Patient-centeredness during in-depth consultation in the outpatient clinic of a tertiary hospital in Korea: paradigm shift from disease to patient. J Korean Med Sci. 2019;34:e119.

28. Wright AA, Zhang B, Ray A, Mack JW, Trice E, Balboni T, et al. Associations between end-of-life discussions, patient mental health, medical care near death, and caregiver bereavement adjustment. JAMA. 2008;300:1665-73. 